Search For The Hero: An Investigation into the Sports Heroes of British Sports Fans

\author{
Keith D. Parry \\ School of Services Management \\ Bournemouth University \\ Talbot Campus, Fern Barrow \\ Poole, Dorset, BH12 5BB \\ Tel: $+44(0) 1202965886$ \\ email: kparry@bournemouth.ac.uk
}

Submitted $31^{\text {st }}$ July 2008 


\title{
Search For The Hero: An Investigation into the Sports Heroes of British Sports Fans
}

\begin{abstract}
This is an initial study into British sports fans' heroes. A questionnaire was administered to 95 students (average age $=19.75$ ) to identify their sporting hero, the hero's sport and nationality and the reasons for this choice. Football was the most common source of sports heroes, identified by 49 percent of participants with a sporting hero. The majority (60 percent, $N=48$ ) of heroes chosen by participants were British with David Beckham the most popular choice. Differences were observed between the gender of participants, gender of hero chosen and the reasons for choosing the hero. The most common reason for selecting a hero was a personal trait rather than skill while a category of Local Affiliation was added to those suggested by previous work. It was concluded that to become a hero athletes should combine skill with devotion to family, charity work and a place in popular culture.
\end{abstract}

\section{Introduction}

Sport emerged as a global phenomenon in the late twentieth century [1] now offering a means of escape from the tedium of the everyday for millions of people across the world [2]. The growth in media resources has helped the rise in popularity of sport across the globe [3] and sport is now at a point where it is seen as an important part of modern society [4]. Whannel highlights how even those who "hate the importance bestowed on the sport feel compelled to write about it" [5]. The growth in popularity has led to top athletes now being recognised across the globe by males and females alike and even by those with little or no interest in sports, mainly due to media portrayal [6]. With this rise in recognisable athletes it is becoming more apparent that people are looking up to the sporting world for their role models and heroes. This study aims to build on previous work into the area of sports fans' heroes and will investigate the qualities which are looked for when a sports hero is selected by British sports fans. Though a number of previous investigations have looked at this topic they have focussed on North American and New Zealand youths. This study aims to bridge the gap in terms of knowledge of the sporting heroes chosen in Britain and will offer a comparative study to these. 
The area of sports heroes is being recognised as an increasingly important subcategory of the wider heroes category with sporting halls of fame becoming more common and fans worshipping their heroes in a quasi-religious form [7]. Though Crawford has identified the important role in society which sports fans play [8], Greenwood et al [9] stress the importance of more research into these consumers of sport.

At present there are a number of gaps in our knowledge in this area. Firstly, there is a paucity of studies looking at sports heroes of British fans. Britain is sociologically and sportingly diverse from North America [10], and so it is expected that there will be significant differences in the heroes chosen within the UK. This study will ask British sports fans to identify their heroes and also to elicit the reasons for their choices. Secondly, there is also an inequality in research in this area between genders. Many sources automatically assume that sports heroes are male [11] and most studies do not look for gender differences in the reasons for choosing a hero.

The purpose of this paper is to identify if there are differences between the sports heroes chosen by British sports fans when compared to those in North America and New Zealand and to discover what these differences are. The paper firstly details the role which sports heroes play, discusses previous work carried out in this area and then uses a survey to elicit the views of British sports fans. At this stage this study is an initial pilot to elicit if there are differences in the sporting heroes chosen in Britain and is part of a continuing investigation into the sporting heroes of the British. As this study will be focused on British consumers the term Football will be used to refer to Association Football (Soccer) while "hero" and "heroes" will be used to refer to male and female athletes alike.

\section{The need for a sporting hero}

Crepeau [12] discusses that society needs heroes to "show us what we ought to be, and we make him a hero because we wish to be what he is" (note the use of the masculine "he" here when referring to a hero, this will be discussed later). This would suggest that heroes should 
be people who society can look up to and try to emulate; they should in essence be good role models for society. Wann et al highlight the importance to society of heroes and identifies six different functions which heroes can play in society; leadership, idealised social order, compensatory, interpersonal involvement, fitness motivation and economic [13]. This extensive list indicates the many different roles which heroes play and the importance to modern society.

The actual concept of the "hero" is problematic to define and the words hero, star, celebrity and icon are often used interchangeably in our modern vocabulary [14]. This raises the question of what exactly is meant by a "hero." Vande Berg [15] discusses that the meaning of the word hero has evolved from its origination in classical Greek society to be now adaptable to different cultures and times. During the Victorian era, for example, it was the attributes associated with being "gentlemanly" along with masculinity which were idolised and associated with heroism [16]. Johnes discusses the case of Fred Keenor, a Welsh footballer who played in the early twentieth century, who was similarly revered for his embodiment of "the working class masculine ideal" [17]. Lines [18] goes on to suggest that the earliest form of a hero reflected traditional ideals which, over time, has increasingly begun to reflect modern society and now encompasses aspects of celebrity and commercialisation. Mailer suggests that the term hero can mean different things to each individual and notes that a hero "embodies a fantasy and so allows each private mind the liberty to consider its fantasy and find a way to grow" [19]. Ingham et al [20] go on to offer two possible justifications for elevation to hero status, either as reward for civic services or recognition as a public figure (both over a number of years). Cashmore and Parker [21] have identified that to be raised up to hero status people are converted into objects to be worshiped and idolised. This lack of clarity regarding the meaning of a hero is picked up by Ingham et al [22], who discuss the need for an in-depth investigation into sports heroes. Athletes who prove their athletic prowess are rewarded with fame and wealth [23] though ability is not sufficient for an athlete to be chosen as a hero. Woolridge, for example, identifies that football "stars" are awarded hero status because they possess a particular image [24]. The image which is identified is likened to that of a film star and is as much about how they live and what they do and is 
based on a variety of cultural types which are embodied by male stars. Woolridge suggests Spicer's typology can be transferred to footballers with categories such as "ordinary bloke", "hard man" and "dandy/glamour boy"; all of which have strong masculine connotations [25].

In the modern world it appears that entertainment and sports are the major fields from which heroes are drawn [26]. That there is a link between sports and entertainment is perhaps not surprising as Holt [27] describes how sporting heroes are now "performer and celebrity, an ostensibly classless product of market values and the media." Athletes such as American Basketball star Michael Jordan have crossed over into the realm of entertainment by appearing in Hollywood films [28] and the British Footballer David Beckham was the subject of a 2002 film title, Bend It Like Beckham [29]. This tie between sport and entertainment is not a modern phenomenon. In a study of the stars of late $19^{\text {th }}$ and early $20^{\text {th }}$ century English football, Woolridge argues that from the outset of professionalism "football stars should be seen as entertainers" [30]. In the case of the most popular sport in Britain, Football, heroes have evolved over time though it is suggested that it was not until the Second World War [31] or alternatively the 1960s that football heroes started to emerge as true national heroes [32] which were accepted within society.

\section{Why athletes are selected as heroes}

As noted earlier, to be a sports hero it is not enough just to have outstanding athletic ability. Lines [33] draws attention to the fact that, despite his status as one of the greatest tennis players of all time, Pete Sampras failed to achieve hero status with the media and public. Athletes must also conform to the ideological practices and beliefs which are accepted by the masses [34]; a mere athlete may have fame but a hero must have more [35]. It appears that we want our heroes to have not only outstanding levels of skill yet they must also entertain us to a certain degree and fit our modern ideology of what it means to be a man/woman in the twenty-first century. Often the public fail to identify with athletes who, it appears, are exemplified by the iconic catchphrase "Show Me the Money!" [36]. Juffer [37] has discussed the humble and apparently non-financially driven qualities attributed to Baseball player Sammy Sosa which led to him emerging as a major star within the United States. Juffer goes 
on to highlight that Sosa is favourably compared to Mark McGwire (another baseball star) whose image was tainted by divorce. It appears that in an age when an increasing number of high profile athletes are making national and international headlines for criminal activities, some of which involve crimes of a sexual nature [38], then the public want their heroes to have images which reinforce the qualities which we hold as valued in society. Sports heroes have to strike a balance between imperfections which make them appear mortal and similar to the general public and crossing the line into major transgressions which alienate them from their fans [39].

At this point it is appropriate to make a comment on the issue of gender as this is an important topic within sports sociology [40]. The majority of heroes chosen are inherently male and masculine [41]. Female athletes elevated to hero status differ from that of their male counterparts, they are often venerated for their femininity rather than their athletic prowess and these heroines are constructed for the "male gaze" [42]. The topic of image of female athletes is part of a much wider discussion and it has been noted that these athletes are often seen as masculine or unladylike [43] or in more aesthetically pleasing sports the focus is on femininity and ideal bodies [44]. There is a clear discrepancy here behind the justifications (at least in the media) for why certain athletes receive more attention than others do.

\section{Who is chosen as a sporting hero?}

Recent years have seen a number of studies into the heroes of sports fans, such as Stevens et al's [45] study into the heroes of 888 Canadians born since 1978, the so-called Generation Y. In response to the question "Who is your favourite hero?" of the 56 different responses the top three recorded were "father" followed by "mother" and then the retired American Basketball star, Michael Jordan, was tied for third place with Canadian Ice Hockey legend, Wayne Gretzky [46]. Their findings further reveal that family members occupied six of the top ten responses whilst a friend or coach and teacher filled the remaining two spots. It is clear that though sports stars are important to those participating in this study family was deemed as being more important. 
When asked the more specific question "Who is your favourite sport hero?" the answers were more diverse. This time 216 different answers were given with the top five recorded as being Michael Jordan, Wayne Gretzky, Donovan Bailey, Mia Hamm and Tiger Woods [47]. It is interesting to note that of the top five only two of those selected were Canadian and the remainder were American. It appears that the major world power is for some nations the major source of sports heroes also. Michael Jordan, the most popular choice, is actually noted for his exploitation of his "mediated image as American, male, family man" to capture a global market [48]. The importance of male heroes being seen as family orientated has been mentioned previously as a recurring theme and is again picked up on by Juffer in her discussion of Sammy Sosa [49].

Stevens et al, in their aforementioned study of Canadian youths, identified five general themes as to why athletes were selected as a hero (personal trait, pro-social behaviour, athletic skill, celebrity statues and adhesion for other reasons i.e. activity/social) [50]. Children identify athletic ability as a highly valued commodity and hence elite athletes can hold considerable influence over them [51]. Their study stresses that media coverage allows children to discern the perceived attitudes, beliefs and behaviours of the sports heroes which they adhere to. As children are highly impressionable at a young age it is important that an understanding of who and why they (and adults alike) are selecting as heroes is gathered to ensure that children are not trying to emulate heroes with suspect characters. An earlier study of Canadian youngsters by Russell and McClusky found that sport was one of the five different categories from which heroes were selected [52]. The study also found that Canadian boys were more likely to have a sporting hero than girls.

Melnick and Jackson studied the heroes of 510 New Zealand youths (average age 14.5 years) and found that the largest proportion (three-quarters) of heroes was drawn from a broad category which they deemed as 'entertainers' which included sports players [53]. As discussed previously this link between sport and entertainment is significant and may reflect on shared qualities which heroes from these fields will share. Within this entertainment 
category the largest (46.7 percent) sub-category was found to be athletes and again the list was again topped by Michael Jordan [54]. As with Stevens et al's Canadian study the largest proportion of these heroes was American and as discussed by Melnick and Jackson this may be a result of media consumption patterns with American films and television shows increasingly popular in New Zealand.

Within the United Kingdom, Phelps has built on the work of Holt to discuss how the characteristics of sports heroes chosen exhibit regional variations [55]. Heroes chosen by fans from the North of England have typically been selected for their toughness and effectiveness with Southern fans more inclined to pick someone who demonstrates a gentlemanly manner and high skill levels. The sport which is perhaps most associated with heroes is football, unsurprisingly due to the global popularity of football and professional football clubs use their past heroes to embody past glories and successes with statues and images of past stars erected outside grounds such as Manchester United and Liverpool [56]. As mentioned previously there is a lack of research into the sporting heroes of the British people and as such this paper aims to answer the following research questions:

1. Who do British University students select as their sporting hero?

2. What are the reasons for the selection of a hero?

3. How do these compare with previous studies?

4. Does gender play a role in hero selection.

\section{Methodology}

A one-page questionnaire was developed to explore the nature of sport heroes. The first section asked basic demographic data containing age, gender and ethnicity. The questionnaire went on to identify from which area of society participants drew their heroes. The categories for this were based on those identified by Russell and McClusky of; Sports, Entertainment, Friends, Relatives and Miscellaneous [57]. Participants were further asked the number of general heroes which they purported to have and then more specifically the number of sports heroes using a five point scale with responses None (1), One (2), Few (3), Some (4) and Many (5). Participants were then asked to identify their primary hero and the 
reason for this choice, using open questions. The survey also included questions to investigate any correlation between heroes chosen and participants' own sporting role, gender and nationality. Qualitative responses were subsequently coded to allow all data to be analysed using SPSS.

A purposive sample of 95 students (59 males and 36 females) provided data for this study which was conducted during February 2008. The participants were all students attending Bournemouth University (BU) on the South coast of England and were studying one of six sports related degree courses offered by BU. A number of previous studies into sports fans have utilised sports students for surveys [58] and it is expected that such students will have a knowledge, interest and understanding of sport related areas to be able to contribute to this study.

\section{Participants}

The questionnaire was administered to 95 University students, (male 62.1 percent, $\mathrm{N}=59$, female 37.9 percent, $N=36$ ) in February 2008. Participants had an average age of 19.75 years $(S D=2.39)$. Football (soccer) was the most common sport played across all participants (35.8 percent, $\mathrm{N}=34$ ) however for females field hockey was the most common response $(16.67$ percent, $N=6)$. Participants were studying sports related courses and were predominantly British.

\section{Results}

Eighty seven percent of participants responded that they identified with at least one hero. Sport was by far the most common area which participants drew their heroes from (80percent) followed by TV/Film (9.5 percent), Music (8.4 percent), a Relative (6.3 percent), Other (3.2 percent) and lastly Politics (1.1 percent). 82.1 percent $(\mathrm{N}=78)$ of the participants identified with a sporting hero, (89.8 percent of males compared to 75 percent of females). In total 60 different sports heroes were selected. The top five selected heroes were David Beckham ( $n=5)$, Steven Gerrard (4), Alan Shearer, Eric Cantona and Matthew Le Tissier (3 each). There were gender differences in the choice of hero however. For males, the 
footballers Steven Gerrard, Eric Cantona and Alan Shearer were the joint most common sports hero (3 each) while for females David Beckham was clearly the most commonly selected hero (4). It is interesting to note that compared to the studies in Canada and New Zealand Michael Jordan did not appear once. Of the top five heroes seen by Stevens et al only Tiger Woods makes a solitary appearance. In addition, in contrast to previous studies the top five selected heroes were footballers and this was the most prevalent sport for both male and female respondents (49.4 percent in total). Of the ten female sports heroes only Paula Radcliffe (British Long Distance Runner) was selected more than once. Table 1 shows a simple cross tabulation of Hero's Sport and the Hero's Gender.

\section{INSERT TABLE 1 ABOUT HERE}

In contrast to previous studies by Stevens et al and Melnick and Jackson [59], the majority (55 percent, $N=43$ ) of heroes chosen by participants were English. If this is combined with the Welsh, Scottish and Irish heroes which were also selected the total is over 60 percent from the British Isles and Ireland $(\mathrm{N}=48)$. However the design of the study was such that regional variations in sports heroes were not identified as in Phelps' 2001 study. 86 percent of the heroes selected were male and not a single male participant chose a female athlete as a hero. However the majority of female respondents (59.3 percent) indicated that they had a male sports hero (see table 2). Males most commonly reported to have few sporting heroes while the modal class for females was one hero. This gender difference is statistically significant $\left(X^{2}(4)=10.84, \rho<0.029\right)$. This corresponds with findings reported by Russell and McClusky who found that boys had on average more sporting heroes than girls [61]. The number of heroes also varies with age, as shown in table 3. Though a corresponding peak is seen in late-teens there is a second peak between the ages of 23 . However the low frequencies may account for this discrepancy with previous studies by Harris [61].

INSERT TABLES 2 AND 3 ABOUT HERE 
Stevens et al categorised the reasons for choosing a hero into five traits; Personal, ProSocial, Skill, Celebrity and Other Reason [62]. Following initial analysis of the free text responses to this question a further category of Local Affiliation is added. This trait was associated with respondents' comments such as "plays for local team" or "Plays for favourite team". The inclusion of this category is supported by research such as Taylor [63] who discuss that the earliest modern sports heroes were local figures. The most common factor which was identified was Personal Trait with comments such as "determination", "attitude", and "passion" being used to describe this trait. The next most popular reason was the skill of the athlete. It is also interesting to note that all instances which were classified as Celebrity correspond to female respondents indicating that a male sports hero was physically attractive - in all three instances the heroes chosen were footballers. The words used to describe these athletes were "attractive" and "good looking." The Local Affiliation trait was identified by 10.5 percent of all respondents and the reasons indicated that the heroes came from either their local or favourite team (see table 4). These results, though not statistically significant at the $5 \%$ level $\left(X^{2}(5)=9.66, \rho<0.086\right)$, do show differences between genders with differences in the Local Affiliation and Celebrity.

\section{INSERT TABLE 4 ABOUT HERE}

\section{Discussion}

Age

Given the ages (mean $=19.75$ ) and backgrounds of the participants it is perhaps not surprising that athletes are most frequently identified as a hero for the respondents in this study. The participants involved were studying sports related degree courses and so a strong level of identification with sport is to be expected. As pointed out by Carr and Weigand, children hold elite athletes in high regard and are heavily influenced by them [64], so, as the participants in this study have an average age of less than 20 they are still comparatively youthful and could be expected to still adhere to elite athletes. This average age also approximately equates to the peak age in late teens for adhering to sporting heroes as identified by Harris [65]. That the sporting world provides the largest source of heroes 
corresponds with the results of Melnick and Jackson [66] who found that sporting figures were the biggest source of heroes for New Zealand youngsters. However these all contradict those of Wann et al [67] who state that friends, relatives and entertainment figures were larger sources of heroes that the sporting world for adults. There are two possible explanations for this; firstly that due to their low average age participants may have more characteristics akin to children rather than adults; or it may be due to their deeper interest in sport as reflected in their decision to read for a degree in this area.

\section{Nationality of Hero}

In contrast to the studies of Stevens et al and Melnick and Jackson [68] the most common nationality of sports hero was British as opposed to American. This reflects the relatively strong and independent sporting and cultural identity of Britain [69] when compared to Canada and New Zealand. In Britain, sport (and entertainment) coverage is predominantly focussed on traditional British sports and the most commonly played and watched are distinct to those played in America; as a result the predominance of British athletes is not surprising. American athletes were the second most popular choice of heroes though the percentages of these athletes is much lower than that recorded in previous studies; 9.5 percent when compared to 36 percent found by Melnick and Jackson [70]. Of the 19 different nationalities for hero's gender 13 of these were European countries which (as the majority of respondents were British) may reflect the proximity of these countries to Britain and it is interesting that the most common European nationality is Britain's nearest neighbour, France. A deeper look at the heroes selected may indicate a different reason however. The two French athletes were Eric Cantona and Thierry Henry, both of whom are footballers who for many years plied their trade within English football and emerged as star players for Manchester United and Arsenal, respectively. A number of other identified European heroes, such as Italian Gianfranco Zola, Danish Peter Schmeichel and Dutchman Dennis Bergkamp were also top players for their respective teams within English football. This may suggest that some sports fans identify with players for their qualities or performances for a team rather than on nationalistic reasons. This theme of "denationalisation" is picked up on by Poli [71] who affirms that the increased migration of sports stars is reducing the territorialisation of identity with regard to sports 
teams. Although Millward [72] has found that in instances of poor results it is foreign players that are blamed first, it does appear that many imported players are accepted and admired by British fans. Athletes such as Tiger Woods and Muhammed Ali only appear once as a hero which is surprising. Woods has appeared on the list of sports heroes for New Zealand youths [73] and Ali has been identified as Sportsman of the Century by the BBC [74] so both have impressive pedigrees. In searching for an explanation for the exclusion of Ali the one reason which may explain this is the age of the participants. Ali's last fight was in 1981 and as all but one of the participants was aged 24 years of age or below they would not even have been alive to witness neither Ali fight nor the charisma for which he was also renowned.

\section{Differences between Sports}

The sport which the chosen hero plays also shows a marked distinction in this instance from the Canadian and New Zealand studies as football is by far the most commonly selected sport to draw heroes from in this study. Martinez [75] discusses that national sports are the biggest source of sporting heroes and so, as football is the national sport of England [76], it is to be expected that this would be the greatest source of sporting heroes. Dunning, Wharton and Natali [77] highlight that it is not only in Britain that Football plays an important role in society and that football is now the most popular sport globally. It is of note that 11.6 percent $(N=11)$ of respondents identify with a football hero even though their chosen sport was not football. The nationality of footballers selected as heroes may also reflect this as the countries represented are as diverse as Trinidad and Italy. The other sports which were seen as most popular were Rugby (Union) and Golf (the figure for golf may be biased as one of the degrees which students study is golf specific). Rugby's popularity in England has grown over recent years due to the success of the national team winning the Rugby World Cup in 2003 and reaching the final in 2007. However rugby is split into two codes and the League form of the game is more popular in Northern England so it would be interesting to see if a similar result would be seen if this study was carried out in a different geographical region of England. It is interesting to note that the one surprising omission from this list of top sports (when compared to national sports) is cricket. Traditionally one of the national sports of England only two heroes were cricket players and one of these was Indian rather than English 
/ British. This particular hero was Sachin Tendulkar the Indian "superstar" who, in India at least, is revered in almost god-like proportions [78]. The lack of cricket heroes is puzzling as 6 percent of respondents indicated that cricket was the sport which they played most frequently yet only two of these selected a cricket hero. Of the top cricket players (and those most frequently highlighted in the media) it is surprising that Kevin Pietersen, the England batsman and one of the top players in the world, has not been selected even once as he plays for the nearest professional cricket club which is based in Southampton (see later for a discussion on local affiliation).

\section{Gender Differences}

There are clear gender differences present here, in terms of both hero's gender and the selection of hero by male and female participants. Firstly the vast majority of heroes selected are male ( 86 percent) which reflects that sport has traditionally been a male dominated sphere [79]. Within this however there are variations as there is a statistically significant difference between the choice of hero (in terms of hero's gender) between male and female participants. No male respondents chose a female athlete while almost 60 percent of female respondents indicated that they admired a male athlete and the most commonly selected hero by females was David Beckham. That females will look up to a male athlete as a hero may be explained by the disproportionate number of male athletes, compared to female athletes, which are available role models with Lines [80] indicating that "feminine sports heroines are both invisible and questionable as sporting role models for young girls". Media coverage is disproportionately focussed on male athletes [81] and as the link between media and selection of hero has been previously highlighted [82] this is another possible explanation for this. Given that the number of female sports fans is increasing [83] alternative rationalisations for this have been identified under the reasons for choosing a hero as many of the reasons given relate to attributes aside from Beckham's skills as a footballer. With the heroes chosen some interesting gender differences can be viewed from a cursory examination though statistical testing of this association is not possible. Of the traditionally male dominated (and more physical sports) such as Football and Rugby Union there is only one hero from a total of 49 who is female and similarly golf is dominated with male heroes. Kay [84] suggests that 
one of the traditional reasons given for why females should not participate in sport was that it was unfeminine and aesthetically unpleasing which, in the case of Football and Rugby, have historically been given as reasons for why women should not participate. These three sports have historically been dominated by men and golf has traditionally been very resistant to integrating female golfers; as a result coverage of these sports is almost exclusively focussed on the male forms of the game [85]. The sports which female heroes are drawn from include gymnastics, athletics, (ice) skating, tennis, badminton and (field) hockey. These sports have traditionally been more acceptable for females to participate in and receive comparable coverage with the male versions and in some cases include mixed forms of the sport where males and females compete together (skating, badminton, tennis and hockey).

\section{Regional Variations}

Phelps postulates that traditional "working class" sporting heroes have been less important in Southern England [86]. Despite almost 10 percent of participants indicating that they selected their hero because of a local connection due to a lack of specific information on the background of participants it has not been possible to investigate geographical differences further. An inspection of the heroes selected by these participants reveals a spread of athletes from across England. In terms of the clubs which the heroes have played for and the relative popularity of "local" Matthew Le Tissier (who played for Southampton Football Club, less than 40 miles from Bournemouth where this study was conducted) hints that even players at south coast clubs do have an important role in local identity. If it had been possible to elucidate where respondents were from it may have been possible to uncover whether those who selected heroes such as Le Tissier were local to the club played for by that hero. The free responses for reason for choosing Le Tissier as a sports hero did not identify Local affiliation as the main reason - the reasons were attributed to his skill levels rather which does correlate with Phelps' assertion that amongst southern fans it is skill and grace which is most admired.

Reasons for Selection 
The most commonly given reason for selection of a hero was a Personal trait and was associated with words which refer to qualities such as "determination", "leadership", and "attitude". Skill was only the second most commonly selected trait which further reinforces that, as found by Chung [87], it takes more than athletic skill to be seen as a hero. This may correspond with people wanting to be able to relate to a hero and recognising that qualities such as determination are valuable in society and which all can hope to attain as identified by Wann et al [88] under their category of Idealised Social Order function for heroes. Other themes which arise within this category also reflect some of the other functions of heroes which Wann et al identified, for example Leadership qualities and in one instance interpersonal involvement. The category of Local Affiliation is the third most common reason for selecting a sports hero. This highlights that local identity plays an important part in people adhering to a hero. That only three respondents adhered to a particular hero for celebrity status is surprising. Taylor, Smart and Boyle and Haynes [89] all affirm that sports heroes are often seen as performer and celebrity, "an ostensibly classless product of market values and the media" [90] so it would perhaps be expected that more heroes would be selected for this reason. As mentioned previously an examination of the exact reasons given within this Celebrity Adherence category all refer to the physical attractiveness of the male athlete to female fans. As with the stereotypical image of female heroes being selected for their physical attractiveness and femininity [91] it now appears that some male athletes are selected for their physical attractiveness. That male footballers are recognised and adhered to for this quality is exemplified by David Beckham, the first man to appear on the front of Marie Claire, the women's magazine, a sex symbol for women [92] and the athlete most frequently linked with attractiveness by respondents in this study. As discussed, there were no female athletes chosen for their physical attractiveness which, despite a wealth of research [93] indicating that this is the main reason why the media focuses on female athletes, for male sports fans this is not a sufficient reason for them to select them as a hero.

There are similarities to be drawn between the athlete who was most commonly selected in this study, David Beckham, and the one selected in the studies by Stevens et al and Melnick and Jackson, Michael Jordan [94]. Both are admired not just for the athletic ability; both have 
crossed from sports into popular culture and have appeared in or been the subject of films such as Bend It Like Beckham, Goal and Space Jam; both are renowned for being family men and both became brand names which were used to aid shirt sales for their respective clubs and earn the athletes vast sponsorship deals [95]. Woolridge has discussed how sports heroes are now comparable with film stars who combine the "extraordinary" (their sporting prowess) yet also can still be seen as "ordinary" and are not too removed from their fans [96]. These ordinary characteristics can be taken to be their familial responsibilities and commitment to their sports. Jordan is involved with numerous charities, many of which focus on supporting children and Beckham is also a UNICEF ambassador [97]. These charitable commitments add to their caring family images and may account for some of Beckham's popularity with female fans as found in this study.

It is interesting to note Beckham himself has expressed that Jordan is one of his sports heroes and now wears the number 23 which Jordan made famous during his basketball career. Furthermore both Beckham and Jordan have become synonymous with sporting skills and ability which are now ingrained in popular culture with the terms "Air Jordan" and "Bend It Like Beckham". It appears as if the skills of both Beckham and Jordan have been identified as being so much above those of their peers that they are the perfect exemplar of these particular athletic abilities. As discussed by Barnes in an article in The Times newspaper on March $28^{\text {th }} 2008$ despite all the faults which Beckham has he is still loved by the British public and this is reflected in his selection as a sporting hero. Following Beckham's move to America in 2007 to continue his playing career with the L.A. Galaxy it remains to be seen if his popularity as a sports hero in America will rise. American audiences may or may not welcome Beckham in the same way that British audiences have taken to him, however his successful move to Spain to play for Real Madrid highlight his adaptability and global charm.

\section{Conclusion}

From this study it is clear that sports fans in Britain are distinct from their peers in North America and New Zealand when it comes to selecting their sports heroes. The majority of 
athletes chosen by British fans were British and predominantly were chosen from Football. British fans are more likely to choose a British sports hero as compared to American as has previously been found. It appears that female fans are as likely to choose a male hero as a female hero though in some instances this may be due to the physical attractiveness of the athlete rather than their levels of skill. The most common characteristic for selecting a hero come with the class defined as Personal Traits and was associated with traits which fans could associate with and perhaps aspire to such as determination and attitude. While the actual skills of the athlete were important (second most common reason) it seems that, as has been previously suggested, to be a sporting hero an athlete must have levels of character and charisma for fans to adhere to them. The most popular hero in this study, David Beckham, shares many characteristics with the athlete who has topped previous studies, Michael Jordan. This suggests a possible framework which athletes could adhere to if they want to become heroes; their athletic ability must be at a high level, they should be devoted to their family, they should engage in charity work and finally (and perhaps most difficultly) they should cross into popular culture. It appears as though the goal of becoming a true sports hero requires much more than just on-field ability in modern sport. This pilot study will form the basis for a more in-depth study of the heroes of British sports fans which will investigate if the findings reported here are reflected in a larger sample. Further work is required to devise a definition of sporting heroes which will stand up to the modern world and which will distinguish between the interlinked terms such as hero and celebrity.

\section{Notes}

1. Smart, The Sport Star

2. Seagrave, 'Sport as a Cultural Hero-System: What Price Glory?'

3. Bolsmann and Parker 'Soccer, South Africa and Celebrity Status: Mark Fish, Popular Culture and the Post-Apartheid State'

4. Dunning, Sport Matters: Sociological Studies of Sport, Violence and Civilization

5. Whannel, 'From Pig's Bladders to Ferraris: Media Discourses of Masculinity and Morality in Obituaries of Stanley Matthews', 75

6. Lines, 'Villains, fools or heroes? Sports stars as role models for young people' 
7. Wann, Melnick, Russell and Pease, Sports Fans: The Psychology and Social Impact of Spectators

8. Crawford, Consuming Sport: Fans, Sport and Culture.

9. Greenwood, Kanters, and Casper, 'Sport Fan Team Identification Formation in MidLevel Professional Sport'

10. Dunning, Sport Matters: Sociological Studies of Sport, Violence and Civilization

11. See Crepeau, 1981 for an example of this.

12. Crepeau, 'Sport, Heroes and Myth', 24

13. Wann, Melnick, Russell and Pease, Sports Fans: The Psychology and Social Impact of Spectators

14. Bolsmann and Parker 'Soccer, South Africa and Celebrity Status: Mark Fish, Popular Culture and the Post-Apartheid State'

15. 1998 cited in Lines, 'Villains, fools or heroes? Sports stars as role models for young people'

16. Holt, Sport and the British: A Modern History

17. Johnes, 'Fred Keenor: A Welsh Soccer Hero', 110

18. Lines, 'Villains, fools or heroes? Sports stars as role models for young people'

19. 1968 cited in Ingham, Howell, and Swetman, “Evaluating Sport "Hero/ines”: Contents, Forms, and Social Relations', 198

20. Ibid

21. Cashmore and Parker, 'One David Beckham? Celebrity, Masculinity, and the Soccerati'

22. Ingham, Howell, and Swetman, 'Evaluating Sport "Hero/ines": Contents, Forms, and Social Relations', 202

23. Chung, H. 'Sports Star Vs Rock Star in Globalizing Popular Culture: Similarities, Difference and Paradox in Discussion of Celebrities'

24. Woolridge, 'Mapping the Stars: Stardom in English Professional Football 1890-1946'

25. Ibid, 54

26. Lucifora, and Simmons, 'Superstar Effects in Sport: Evidence From Italian Soccer.' 
27. 1998 cited in Taylor, 'Football, History and Memory: The Heroes of Manchester United.', 26

28. Cashmore and Parker, 'One David Beckham? Celebrity, Masculinity, and the Soccerati'

29. Smart, The Sport Star

30. Woolridge, 'Mapping the Stars: Stardom in English Professional Football 1890-1946', 67

31. ibid

32. Taylor, 'Football, History and Memory: The Heroes of Manchester United.'

33. Lines, 'Villains, fools or heroes? Sports stars as role models for young people'

34. Chung, 'Sports Star Vs Rock Star in Globalizing Popular Culture: Similarities, Difference and Paradox in Discussion of Celebrities'

35. Ingham, Howell, and Swetman, 'Evaluating Sport "Hero/ines": Contents, Forms, and Social Relations'

36. From the 1996 film Jerry Maguire by director Cameron Crowe

37. Juffer, 'Who's the Man? Sammy Sosa, Latinos, and Televisual Redefinitions of the "American" Pastime'

38. Lines, 'Villains, fools or heroes? Sports stars as role models for young people' and Coakley, Sport in Society: Issues and Controversies.

39. McDorman, Caspar, Logan and McGinley, 'Where Have All the Heroes Gone? An Exploration of Cultural Therapy in Jerry Maguire, For Love of the Game, and Any Given Sunday'

40. Dunning, Sport Matters: Sociological Studies of Sport, Violence and Civilization

41. Lines, 'Villains, fools or heroes? Sports stars as role models for young people' and Whannel, 'From Pig's Bladders to Ferraris: Media Discourses of Masculinity and Morality in Obituaries of Stanley Matthews'

42. Lines, 'Villains, fools or heroes? Sports stars as role models for young people', 291

43. Boyle and Haynes, Power Play: Sport, the Media \& Popular Culture

44. Davies, 'The Basic Content: Ideally beautiful and sexy women for men' 
45. Stevens, Lathrop and Bradish, "Who is Your Hero?" Implications for Athlete Endorsement Strategies'

46. Ibid, 106

47. ibid

48. Chung, H. 'Sports Star Vs Rock Star in Globalizing Popular Culture: Similarities, Difference and Paradox in Discussion of Celebrities', 100

49. Juffer, 'Who's the Man? Sammy Sosa, Latinos, and Televisual Redefinitions of the "American" Pastime'

50. Stevens, Lathrop and Bradish, "Who is Your Hero?" Implications for Athlete Endorsement Strategies'

51. Carr, and Weigand, 'Parental, Peer, Teacher and Sporting Hero Influence on he Goal Orientations of Children in Physical Education'

52. 1986, cited in Wann, Melnick, Russell and Pease, Sports Fans: The Psychology and Social Impact of Spectators

53. Melnick and Jackson, 'Globalization American-Style and Reference Idol Selection: The Importance of Athlete Celebrity Others among New Zealand Youth'

54. Ibid, 437

55. Phelps, 'The Southern Football Hero and the Shaping of Local and Regional Identity in the South of England' and Holt, Sport and the British: A Modern History

56. For Manchester United see Taylor, 'Football, History and Memory: The Heroes of Manchester United.' and for Liverpool see Russell, 'We All Agree, Name the Stand after Shankly": Cultures of Commemoration in Late Twentieth-century English Football Culture'

57. Russell and McClusky, 1986, cited in Wann, Melnick, Russell and Pease, Sports Fans: The Psychology and Social Impact of Spectators

58. Melnick, M.J., and Wann, D.L, 'Sport fandom influences, interests, and behaviours among Norwegian University Students'; Theodorakis and Wann, 'An Examination of Sport Fandom in Greece: Influences, Interests, and Behaviours.'; Wann, Melnick, Russell and Pease, Sports Fans: The Psychology and Social Impact of Spectators 
59. Stevens, Lathrop and Bradish, "Who is Your Hero?" Implications for Athlete Endorsement Strategies' and Melnick and Jackson

60. 1986, cited in Wann, Melnick, Russell and Pease, Sports Fans: The Psychology and Social Impact of Spectators

61. Harris 1986 cited in Wann, Melnick, Russell and Pease, Sports Fans: The Psychology and Social Impact of Spectators

62. Stevens, Lathrop and Bradish, "Who is Your Hero?" Implications for Athlete Endorsement Strategies', 106

63. Taylor, 'Football, History and Memory: The Heroes of Manchester United.'

64. Carr, and Weigand, 'Parental, Peer, Teacher and Sporting Hero Influence on he Goal Orientations of Children in Physical Education'

65. Harris, 1986 cited in Wann, Melnick, Russell and Pease, Sports Fans: The Psychology and Social Impact of Spectators

66. Melnick and Jackson, 'Globalization American-Style and Reference Idol Selection: The Importance of Athlete Celebrity Others among New Zealand Youth'

67. Wann, Melnick, Russell and Pease, Sports Fans: The Psychology and Social Impact of Spectators

68. Stevens, Lathrop and Bradish, "Who is Your Hero?" Implications for Athlete Endorsement Strategies' and Melnick and Jackson, 'Globalization American-Style and Reference Idol Selection: The Importance of Athlete Celebrity Others among New Zealand Youth'

69. Dunning, Sport Matters: Sociological Studies of Sport, Violence and Civilization

70. Melnick and Jackson, 'Globalization American-Style and Reference Idol Selection: The Importance of Athlete Celebrity Others among New Zealand Youth'

71. Poli (2007)

72. Millward, 'True Cosmopolitanism or Notinal Acceptance of Non-National Players in English Football: Or, why "bloody foreigners" get blamed when "things go wrong"'

73. Melnick and Jackson, 'Globalization American-Style and Reference Idol Selection: The Importance of Athlete Celebrity Others among New Zealand Youth'

74. http://news.bbc.co.uk/1/hi/sport/561352.stm [Accessed 16th July 2008] 
75. Martinez, 'Soccer in the USA: "holding out for a hero"?'

76. http://www.thefa.com/NR/rdonlyres/000220ac/rylcyedwlcqdskrwpxzyggdugzbhpiru/FA Vision 200812.pdf [Accessed 18th July 2008]

77. Dunning, Sport Matters: Sociological Studies of Sport, Violence and Civilization, Wharton, 'Reflection on the New fiesta nacional(ista); Soccer and Society in Modern Spain' and Natali, 'The Realm of the Possible: Remembering Brazilian Futebol'

78. Nalapat and Parker, 'Sachin Tendulkar, Cricket and Indian Nationalisms'

79. Dunning, Sport Matters: Sociological Studies of Sport, Violence and Civilization and Schimmel, Harrington and Bielby, 'Keep Your Fans to Yourself: The Disjuncture between Sports Studies' and Pop Culture Studies' Perspectives on Fandom'

80. Lines, 'Villains, fools or heroes? Sports stars as role models for young people', 286

81. Billings and Eastman, 'Selective Representation of Gender, Ethnicity, and Nationality in American Television Coverage of the 2000 Summer Olympics'; Vincent, Imwold, Masemann and Johnson, 'A Comparison of Selected 'Serious' And 'Popular' British, Canadian, and United States Newspaper Coverage of Female and Male Athletes Competing in the Centennial Olympic Games: Did Female Athletes Receive Equitable Coverage in the 'Games of the Women'?'; Cunningham, 'Media Coverage of Women's Sport: A New Look at an Old Problem'.

82. Smart, The Sports Star and Woolridge, 'Mapping the Stars: Stardom in English Professional Football 1890-1946'

83. Wann, Melnick, Russell and Pease, Sports Fans: The Psychology and Social Impact of Spectators

84. Kay, 'Sport and Gender'

85. Harris, 'The Image Problem in Women's Football'.

86. Phelps, 'The Southern Football Hero and the Shaping of Local and Regional Identity in the South of England', 44

87. Chung, 'Sports Star Vs Rock Star in Globalizing Popular Culture: Similarities, Difference and Paradox in Discussion of Celebrities'

88. Wann, Melnick, Russell and Pease, Sports Fans: The Psychology and Social Impact of Spectators 
89. Taylor, 'Football, History and Memory: The Heroes of Manchester United.', Smart, The Sports Star and Boyle and Haynes, Power Play: Sport, the Media \& Popular Culture

90. Taylor, 'Football, History and Memory: The Heroes of Manchester United.', 26

91. Lines, 'Villains, fools or heroes? Sports stars as role models for young people'

92. Smart, The Sports Star highlights Beckham appearing in the women's magazine and Beckham as a sex symbol for women is discussed by Cashmore and Parker, 'One David Beckham? Celebrity, Masculinity, and the Soccerati'

93. Dunning, Sport Matters: Sociological Studies of Sport, Violence and Civilization and Davies, 'The Basic Content: Ideally beautiful and sexy women for men'

94. Stevens, Lathrop and Bradish, "Who is Your Hero?" Implications for Athlete Endorsement Strategies' and Melnick and Jackson, 'Globalization American-Style and Reference Idol Selection: The Importance of Athlete Celebrity Others among New Zealand Youth'

95. For crossing from sports into popular culture see Cashmore, E. and Parker, A. 'One David Beckham? Celebrity, Masculinity, and the Soccerati', being family men see Chung, H. 'Sports Star Vs Rock Star in Globalizing Popular Culture: Similarities, Difference and Paradox in Discussion of Celebrities' and for sponsorship deals see Smart, The Sports Star

96. Woolridge, 'Mapping the Stars: Stardom in English Professional Football 1890-1946', 52

97. http://www.unicef.org.uk/celebrity/celebrity biography.asp?celeb id=27 [Accessed $12^{\text {th }}$ July 2008]

\section{References}

Billings, A.C., and Eastman, S.T. 'Selective Representation of Gender, Ethnicity, and Nationality in American Television Coverage of the 2000 Summer Olympics'. International Review for the Sociology of Sport, 37, no.4, (2002): 351-370

Bolsmann, C. and Parker, A. 'Soccer, South Africa and Celebrity Status: Mark Fish, Popular Culture and the Post-Apartheid State' 8, no.1, (2007): 109 - 124. 
Boyle, R. and Haynes, R. Power Play: Sport, the Media \& Popular Culture. Harrow: Longman, 2000.

Carr, S. and Weigand, D.A. 'Parental, Peer, Teacher and Sporting Hero Influence on he Goal Orientations of Children in Physical Education' European Physical Eduation Review, 7, no.3, (2001): $305-328$.

Cashmore, E. and Parker, A. 'One David Beckham? Celebrity, Masculinity, and the Soccerati' Sociology of Sport Journal, 30, (2003): $214-231$.

Chung, H. 'Sports Star Vs Rock Star in Globalizing Popular Culture: Similarities, Difference and Paradox in Discussion of Celebrities' International Review for the Sociology of Sport, 38, no.1, (2003): $99-108$.

Coakley, J. Sport in Society: Issues and Controversies, $9^{\text {th }}$ ed. London: McGraw-Hill, 2007.

Crawford, G. Consuming Sport: Fans, Sport and Culture. London: Routledge, 2004.

Crepeau, R.C. 'Sport, Heroes and Myth' Journal of Sport and Social Issues, 5, no.23, (1981): $23-31$.

Cunningham, G.B. 'Media Coverage of Women's Sport: A New Look at an Old Problem'. Physical Educator . 60, no. 2, (2003): 43-49Davies, L. A. 'The Basic Content: Ideally beautiful and sexy women for men'. In Critical Readings: Sport, Culture and the Media, edited by D. Rowe. Maidenhead: Open University Press, 2004.

Dunning, E. Sport Matters: Sociological Studies of Sport, Violence and Civilization. London: Routledge, 1999.

Greenwood, P.B., Kanters, M. A. and Casper, J., M. 'Sport Fan Team Identification Formation in Mid-Level Professional Sport'. European Sport Management Quarterly, 6, no.3 (2006): 253 $-265$

Harris, J. 'The Image Problem in Women's Football'. Journal of Sport \& Social Issues, 29, no. 2, (2005): $184-197$.

Holt, R. Sport and the British: A Modern History. Oxford: Clarendon Press, 1993.

Ingham, A.G., Howell, J.W. and Swetman, R.D. 'Evaluating Sport "Hero/ines": Contents, Forms, and Social Relations' QUEST, 45, (1993): 197 - 210.

Johnes, M. 'Fred Keenor: A Welsh Soccer Hero' The Sports Historian 1, no. 18, (1998): 105 119. 
Juffer, J. 'Who's the Man? Sammy Sosa, Latinos, and Televisual Redefinitions of the “American" Pastime' Journal of Sport and Social Issues, 26, no.4, (2002): 337 - 359.

Kay, T. 'Sport and Gender' In Sport and Society. Edited by B. Houlihan, London: Sage, 2003. Lines, G. 'Villains, fools or heroes? Sports stars as role models for young people' Leisure Studies 20, (2001): $285-303$.

Lucifora, C. and Simmons, R. 'Superstar Effects in Sport: Evidence From Italian Soccer.' Journal of Sports Economics 4, no.35 (2003): 35 - 55.

Martinez, D.P. 'Soccer in the USA: "holding out for a hero"?' Soccer \& Society, 9, no.2, (2008): $231-243$

McDorman, T.F., Caspar, K., Logan, A. and McGinley, S. 'Where Have All the Heroes Gone? An Exploration of Cultural Therapy in Jerry Maguire, For Love of the Game, and Any Given Sunday’ Journal of Sport \& Social Issues, 30, no.2, (2006): 197 - 218.

Melnick, M.J. and Jackson, S.J. 'Globalization American-Style and Reference Idol Selection: The Importance of Athlete Celebrity Others among New Zealand Youth' International Review for the Sociology of Sport, 37, no.3, (2002): $429-428$.

Melnick, M.J. and Wann, D.L. 'Sport fandom influences, interests, and behaviours among Norwegian University Students.' International Sports Journal, 8, (2004): 1 - 7.

Millward, P. 'True Cosmopolitanism or Notional Acceptance of Non-National Players in English Football: Or, why "bloody foreigners" get blamed when "things go wrong"' Sport in Society, 10, no.4, (2007): $601-622$.

Nalapat, A. and Parker, A. 'Sachin Tendulkar, Cricket and Indian Nationalisms' International Review for the Sociology of Sport, 40, no.4, (2005): $433-446$.

Natali, M. 'The Realm of the Possible: Remembering Brazilian Futebol' Soccer \& Society 8, no.2, (2007): $267-282$.

Phelps, N.A. 'The Southern Football Hero and the Shaping of Local and Regional Identity in the South of England' Soccer \& Society, 2, no.3, (2001): $44-57$.

Poli, R. 'The Denationalization of Sport: De-ethnicization of the Nation and Identity Deterritorialization' Sport in Society, 10, no.4, (2007): $646-661$.

Russell, D. "We All Agree, Name the Stand after Shankly": Cultures of Commemoration in Late Twentieth-century English Football Culture' Sport in History 26, no.1, (2006): 1 - 25. 
Schimmel, K.S., Harrington, C.L. and Bielby, D.D. 'Keep Your Fans to Yourself: The Disjuncture between Sports Studies' and Pop Culture Studies' Perspectives on Fandom' Sport in Society 10, no.4, (2007): $580-600$.

Seagrave, J.O. 'Sport as a Cultural Hero-System: What Price Glory?' QUEST, 45, (1993): 182 $-196$.

Smart, B. The Sport Star: Modern Sport and the Cultural Economy of Sporting Celebrity. London: Sage, 2005.

Stevens, J.A., Lathrop, A.H. and Bradish, C.L. "Who is Your Hero?" Implications for Athlete Endorsement Strategies' Sport Marketing Quarterly, 12, no.2, (2003): 103 - 110.

Taylor, M. 'Football, History and Memory: The Heroes of Manchester United.' Football Studies 3, no.2 (2000): $24-41$.

Theodorakis, N.D. and Wann, D.L. 'An Examination of Sport Fandom in Greece: Influences, Interests, and Behaviours.' International Journal of Sports Marketing and Sponsorship. In Press.

Vincent, J., Imwold, C., Masemann, V., Johnson, T.J., 'A Comparison Of Selected 'Serious' And 'Popular' British, Canadian, And United States Newspaper Coverage Of Female And Male Athletes Competing In The Centennial Olympic Games Did Female Athletes Receive Equitable Coverage in the 'Games of the Women'?' International Review for The Sociology Of Sport 37, no.4 (2002): 319-335

Wann, D.L., Melnick, M.J., Russell, G.W. and Pease, D.G. Sports Fans: The Psychology and Social Impact of Spectators. London: Routledge, 2001.

Wann, D.L., Shinner, J. and Keenan, B.L., 'Males' Impressions of Female Fans and Nonfans: There really is "Something about Mary"'. North American Journal of Psychology. 3, no 2 (2001): $183-192$.

Whannel, G. 'From Pig's Bladders to Ferraris: Media Discourses of Masculinity and Morality in Obituaries of Stanley Matthews' Culture, Sport, Society, 5, no.3, (2002): 73 - 94.

Wharton, B. 'Reflection on the New fiesta nacional(ista); Soccer and Society in Modern Spain' 8, no.4, (2007): $601-613$.

Woolridge, J., 'Mapping the Stars: Stardom in English Professional Football 1890-1946'

Soccer \& Society 3, no.2, (2002): $51-69$ 
Tables

Table 1: Sport Played By Hero * Hero Gender Crosstabulation

\begin{tabular}{|c|c|c|c|c|}
\hline & & Hero's & nder & \\
\hline & & Male & Female & Total \\
\hline Sport & Athletics & 0 & 2 & 2 \\
\hline Played & Badminton & 0 & 1 & 1 \\
\hline By Hero & Basketball & 2 & 0 & 2 \\
\hline & Boxing & 1 & 0 & 1 \\
\hline & Cricket & 2 & 0 & 2 \\
\hline & Cycling & 1 & 0 & 1 \\
\hline & Equestrian & 1 & 0 & 1 \\
\hline & Football & 38 & 1 & 39 \\
\hline & Golf & 7 & 1 & 8 \\
\hline & Gymnastics & 0 & 1 & 1 \\
\hline & Hockey & 0 & 1 & 1 \\
\hline & Horse Racing & 1 & 0 & 1 \\
\hline & Martial Arts & 1 & 0 & 1 \\
\hline & Rowing & 1 & 0 & 1 \\
\hline & Rugby & 10 & 0 & 10 \\
\hline & Synch Skating & 0 & 1 & 1 \\
\hline & Tennis & 3 & 3 & 6 \\
\hline Total & & 68 & 11 & 79 \\
\hline
\end{tabular}

Table 2: Gender * Hero Gender Crosstabulation 


\begin{tabular}{|ll|r|r|r|}
\hline \multirow{2}{*}{} & & \multicolumn{2}{|c|}{ Hero Gender } & \multirow{2}{*}{ Total } \\
\cline { 3 - 4 } & \multicolumn{1}{|c|}{ Male } & \multicolumn{1}{c|}{ Female } & \multirow{2}{*}{ Tot } \\
\hline Gender & Male & 52 & 0 & 52 \\
& Female & 16 & 11 & 27 \\
Total & & 68 & 11 & 79 \\
\hline
\end{tabular}

Table 3: How Many Sports Heroes Do You Have?

(Using the scale $1=$ None $-5=$ Many)

\begin{tabular}{|l|r|r|}
\hline Age & \multicolumn{1}{|l|}{ Mean } & $\mathrm{N}$ \\
\hline 18.00 & 3.0357 & 28 \\
19.00 & 3.1290 & 31 \\
20.00 & 2.9167 & 12 \\
21.00 & 2.4000 & 5 \\
22.00 & 2.7273 & 11 \\
23.00 & 3.6000 & 5 \\
24.00 & 5.0000 & 1 \\
37.00 & 1.0000 & 1 \\
Total & 3.0106 & 94 \\
\hline
\end{tabular}

Table 4: Why you chose your Hero * Gender Crosstabulation

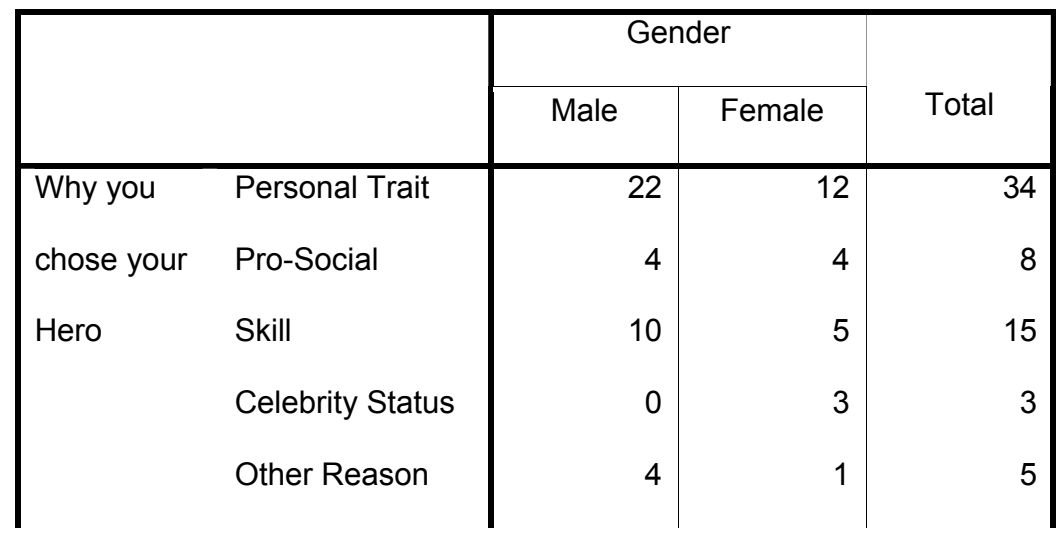




\begin{tabular}{|c|c|c|c|}
\hline Local & 8 & 1 & 9 \\
\hline Total & 48 & 26 & 74 \\
\hline
\end{tabular}

